\title{
La educación laica en Antioquia durante el primer cuarto del siglo xx: una historia de solapamientos y combinatorias*
}

\section{Carlos Arturo Ospina Cruz}

\begin{abstract}
Profesor de la Universidad de Antioquia (Colombia). Correo electrónico: carturo.ospina@udea.edu.co. El autor es doctor en Educación de la Universidad de Antioquia (Colombia) e integrante del Grupo de Investigación sobre formación y Antropología Pedagógica e Histórica -FORMAPH- de la misma universidad. Entre sus publicaciones recientes tenemos: "De maestras, señoritas y otras peripecias pedagógicas. Las mujeres en la historia de la educación en Antioquia (1903-1930)" en Revista Historia y Memoria No. 10 (2015) y "Civilización, educación e instrucción: cuerpos en disputa. El proyecto moderno instruccionista en Antioquia (1903-1930)" en Revista Latinoamericana de Estudios sobre Cuerpos, Emociones y Sociedad Vol. 7 No. 17. Entre sus temas de interés están Historia de la educación, antropología pedagógica e histórica, narrativas, infancia y gestión educativa.
\end{abstract}

\section{Andrés KLaus Runge Peña}

Profesor de la Univesridad de Antioquia (Colombia). Correo electronico: akrp777@gmail.com. El autor es doctor en Educación de Freie Universitat Berlin (Alemania) y coordinador del Grupo de Investigación sobre formación y Antropología Pedagógica e Histórica -FORMAPH- de la Universidad de Antioquia (Colombia). Entre sus publicaciones recientes tenemos: "Didáctica: una introducción panorámica y comparada" en Itinerario Educativo, Vol. 27, No. 62 (2013) y "La pedagogía como campo intelectual: Tensiones en el origen del Movimiento Pedagógico” en Revista Educación y Cultura, No. 100 (2013). Entre sus temas de interés están Historia de la educación, antropología pedagógica e histórica, narrativas, infancia y gestión educativa.

Recibido: 7 de septiembre de 2015

Aprobado: 23 de junio de 2016

Modificado: 27 de julio de 2016

Artículo de investigación científica

DOI: http://dx.doi.org/10.15648/hc.30.2016.5

* $\quad$ Este artículo forma parte del proyecto: "El proceso de apropiación de la Ley 39 de 1903 en Antioquia en la instrucción pública primaria y secundaria hasta el intento de clausura de las Escuelas Normales (1930). Facultad de Educación, Universidad de Antioquia." financiado con recursos propios. Esta publicación está bajo una licencia Creative Commons Reconocimiento-NoComercial 4.0 
La educación laica en Antioquia durante el primer cuarto del siglo xx: Una historia de solapamientos y combinatorias

\title{
Resumen
}

Realizamos un recorrido histórico sobre la presencia de la educación laica en el primer cuarto del siglo XX en Antioquia, puesta en confrontación con las ideologías educativas dominantes. Para ello compilamos elementos que muestran las dinámicas de tal encuentro en la educación de ese periodo a partir de los discursos circulantes para entonces en esta región del país. A posteriori, desvirtuando el espíritu laico que pueden ofrecer los nuevos contextos de la Constitución de 1991 y del siglo XXI, y como naturalización por la costumbre, la enseñanza de la religión y moral doctrinales han devenido en un eje transversal para la educación de niños y jóvenes. Hablar de laicización de la educación en Antioquia es hablar, más bien, de una historia de confrontaciones y conjugaciones con el pensamiento educativo católico dominante.

Palabras clave: moral, escuelas, Antioquia, educación laica.

Secular education in Antioquia during the first quarter of the twentieth century: A history of overlaps and combinatorics

\begin{abstract}
We conducted a historical overview of the presence of secular education in the first quarter of the 20th century in Antioquia, in confrontation with the dominant educational ideologies. For this purpose, we compiled elements showing the dynamics of such encounter in education from circulating speeches in the region by that time. A posteriori, distorting the secular spirit that the new contexts can offer of the 1991 Constitution and the 21 st century, and as naturalization by custom, the religion and doctrinal morality teaching have become in a cross-curricular approach for children and young people education. Talking about secularization of education in Antioquia is mainly speaking of a history of confrontations and conjugations with the dominant educational Catholic thinking.
\end{abstract}

Keywords: morality, schools, Antioquia, secular education.

A educação laica em Antioquia durante o primeiro quarto do século xx: Uma história de sobreposições e combinatorias

\section{Resumo}

Realizamos o percurso histórico sobre a presença da educação laica no primeiro quarto 
do século XX em Antioquia, posta em confrontación com as ideologias educativas dominantes. Para isso compilamos elementos que mostram as dinâmicas de tal encontro na educação desse período a partir dos discursos circulantes para então nesta região do país. A posteriori, desvirtuando o espírito laico que podem oferecer os novos contextos da Constituição de 1991 e do século XXI, e como naturalização pelo costume, o ensino da religião e moral doutrinais têm devindo num eixo transversal para a educação de meninos e jovens. Falar de laicización da educação em Antioquia é falar, mais bem, de uma história de confrontos e conjugações com o pensamento educativo católico dominante.

Palavras-chave: moral, escolas, Antioquia, educação laica.

\section{L'éducation laïque en Antioquia pendant le premier quart du XX ème siècle: une histoire des chevauchements et combinatoires}

\section{Résumé}

Nous avons mis en place un parcours historique sur la présence de l'éducation laïque en Antioquia lors du premier quart du XXème siècle, confrontée aux idéologies éducatives dominantes. Dans ce but nous avons compilé les dynamiques de telle rencontre dans l'éducation de cette période, à partir des discours circulants à ce moment-là, dans cette région du pays. A posteriori, dénaturant l'esprit laïque qui ont pu offrir les nouveaux contextes de la Constitution de 1991 et du XXIème siècle, et en tant que naturalisation par les coutumes, l'enseignement de la religion et morales doctrinales, ceux-ci sont devenus un axe transversale pour l'éducation des enfants et adolescents. Parler de laïcité de l'éducation en Antioquia c'est parler plutôt, d'une histoire de confrontations et conjugaisons avec la pensée éducative catholique dominante.

Mots clés: moral, écoles, Antioquia, éducation laïque.

\section{INTRODUCCIÓN}

A pesar de los diferentes planteamientos acerca del proceso de modernización colombiano y, particularmente, antioqueño durante el primer cuarto del siglo XX reflejado en un cambio acelerado en las estructuras productivas de la región, en su industrialización, su urbanización y la presencia extranjera, se quiere plantear que el proceso formativo de niños y 
jóvenes en este departamento estaba lejos de acercarse a una educación totalmente laica.

A pesar, por ejemplo, de las Misiones Alemanas y del papel en la educación antioqueña de educadores extranjeros como los pestalozzianos Cristian Siegert y Gustav Bothe y el pedagogo Gotthold Weis, las rutas educativas establecidas para la formación de las nuevas generaciones se habían dado gracias a la existencia de una serie de condiciones sociales, políticas, militares e ideológicas conexas entre sí, entre las cuales podemos señalar con mayor fuerza las que tienen que ver con la influencia de la iglesia Católica en el sistema educativo del país y, más particularmente, en Antioquia ${ }^{1}$.

El propósito de este trabajo es hacer un recorrido histórico sobre las vicisitudes de la educación laica en Antioquia durante el primer cuarto del siglo XX y sus permanentes contrapunteos con la educación católica imperante. Para ello, en un primer capítulo contextualizamos algunas discusiones al respecto que se presentaban en el extranjero, o dentro del mismo país pero con incidencia regional en Antioquia. En un segundo capítulo nos acercamos a los discursos circulantes acerca de la educación laica en el sentido de no ofrecer garantías para un orden social enmarcado desde la perspectiva dominante. En el último capítulo miramos la propuesta de Escuela Nueva o Activa como una eventual puerta a un sistema de instrucción laica y las discusiones que se suscitaron en torno a ello. Nuestra idea

1 Por ejemplo, con respecto a estos dos normalistas alemanes: Siegert y Weis, se exigía, para su contrato, que fueran "De religión apostólica, católica y romana". Por su parte, el gobierno central se hacía a los servicios, para ese momento, del pedagogo protestante Gotthold Weis, para que fundara una Normal Nacional en Antioquia. Weis fue rechazado enfáticamente por la sociedad medellinense y, por ello, se ventiló la posibilidad de que estuviera a cargo, más bien, de la fundación de una Normal Nacional en Rionegro, territorio considerado con una mentalidad más liberal para ese entonces. $\mathrm{Al}$ final, el proyecto de fundación de una Normal Nacional se hizo en Medellín, no sin permanentes dificultades, hasta que la Dirección General de Instrucción Pública del Estado Soberano de Antioquia decidió cerrar dicho establecimiento y evitar con ello, además, la rivalidad establecida con la Normal Antioqueña. Esta última, a diferencia, se mantuvo en sus labores desde sus inicios el 1 de agosto de 1972. En ella se implementó una enseñanza pestalozziana, gracias a Siegert y Weis, y se propusieron contenidos y asignaturas como calisténica, gimnástica, música, ejercicios militares. Igualmente, se dio una enseñanza religiosa fuertemente marcada por un tono patriótico. Se esperaba que todo ello sirviera de base para formar a los individuos de manera que Antioquia pudiera enfrentar una posible guerra con los Estados liberales de la República -guerra que efectivamente tuvo lugar en 1876-. Los educadores alemanes Siegert y Weis no solo terminaron organizando una compañía militar al servicio del gobierno conservador y católico, sino que ellos mismos se vieron involucrados como oficiales del ejército. En: El Monitor, Tomo I, Medellín 17 de julio de 1872, p. 218. 
es que la tensión por la estructuración de una educación laica en Antioquia en particular, y en Colombia en general, tiene una trayectoria histórica de mucho más de un siglo que debe ser valorada y conocida, y que no se reduce necesariamente a los planteamientos de diversidad cultural que se desprenden tanto de los prolegómenos como de la Constitución de $1991^{2}$. En tal sentido, las crisis actuales por las que atraviesa la educación pública en Colombia en contextos de diversidad cultural y de respeto por las prácticas religiosas en el primer cuarto del siglo XXI, son miradas aquí en perspectiva histórica en relación con lo que venía ocurriendo en el país, precisamente en el primer cuarto del siglo XX.

\section{Lo CATÓlico Y LO LAICO EN LA EDUCACIÓN: UN PROBLEMA ALLENDE NUESTRAS FRONTERAS}

Un hecho que mostraba ya, desde fines del siglo XIX, las fuertes resistencias de los arraigos cristianos frente a las alternativas de carácter laico en la región antioqueña y que tuvo ribetes internacionales, se puede constatar a partir del cruce de misivas allende el mar:

"En 1874, una asociación francesa a favor de la educación laica escribe a los masones de Bogotá para presentarles su proyecto en contra de la educación católica. Entusiasmados, estos organizan una recolección de fondos para apoyar el proyecto. En fin, ante los ataques del clero colombiano que difunde panfletos antimasónicos europeos, los masones colombianos recurren a los argumentos anticlericales esgrimidos por la masonería europea. Como respuesta a la pastoral de mayo de 1876, en que el obispo de Antioquia, Joaquín Guillermo González, ordena al pueblo católico rebelarse contra un gobierno liberal al que acusa de ser el juguete de la herejía masónica, los masones de Bogotá publican el panfleto publicado en Francia unas semanas antes por el gran orador Malapert en contra del estudio sobre la masonería de monseñor Dupanloup"3.

2 Y de la cual, precisamente, se cumple hace poco el primer cuarto de siglo de haber sido promulgada dejando el siglo XX y abriendo las puertas al siglo XXI.

3 Boletín Masónico, Bogotá, junio 1º, 1876. Citado por Frédéric Martínez. El nacionalismo cosmopolita, 132-133. 
Entre tanto, la popularidad de monseñor Dupanloup entre algunos de los antioqueños que podían darse el lujo de viajar y estudiar en Europa crecía y quedaba en evidencia: "Próspero Restrepo envía desde París las últimas publicaciones de la literatura católica francesa a su hermano Vicente en Medellín"4. Martínez refiere, igualmente, cómo en una carta de 1881 el mismo Vicente le recuerda a Próspero que espera su envío de libros de Monseñor Dupanloup desde el continente europeo. Una de las cosas curiosas que parece quedar señalada con este tipo de eventos, es el hecho de que algunas de las ideas europeas llegaban a Antioquia, sin tener que pasar necesariamente por el puente de la lectura que se realizara de las mismas en la capital (Bogotá).

Además, puede notarse cómo ya desde el tercer cuarto del siglo XIX existe descontento de algunos sectores antioqueños -aquellos que de alguna manera mantenían contacto con Europa como en este caso- con la hegemonía católica en la educación y, a cambio, propugnaban por una educación laica. Puede decirse que esta pugna en territorio antioqueño era, igualmente, reflejo de lo que venía sucediendo para entonces en gran parte del país: De un lado, una tendencia liberal radical que establece desde 1870, a instancias de una misión de pedagogos alemanes, la educación pública, laica, obligatoria, gratuita y basada en la separación entre la iglesia Católica y el Estado. De otra parte, una tendencia conservadora que sigue protegiendo la escuela pública pero con tendencia católica y para ello lanza campañas y guerras entre las que se destaca la guerra civil de 1876-18775.

Todavía más, ya desde el referido año de 1874 Manuel Murillo Toro, jefe del radicalismo liberal y presidente, al presentar su Memoria al Congreso denunciaba la guerra de la Iglesia y el Partido Conservador contra la escuela pública laica, aquella que se venía impulsando oficialmente. El texto de su pronunciamiento es suficientemente claro como para contextualizar la situación que se vivía en los últimos años del siglo XIX y previos a la promulgación de la Ley 39 de 1903: XX. Revista Educación y Cultura. FECODE. Bogotá, Colombia, No. 50-51, (Agosto de 1999) 35. 
"La instrucción primaria, por los métodos alemanes, sigue difundiéndose con notables adelantamientos, no obstante la guerra que le hace el espíritu de partido, auxiliado por las costumbres que dejó la protección que el Estado daba a la Iglesia Católica. Separada esta de aquél, no siendo ya la religión asunto de gobierno, las escuelas y demás establecimientos de enseñanza costeados por él deben abstenerse de toda enseñanza o propaganda religiosa; pero el clero, acostumbrado a descargarse en el gobierno de la obligación de enseñar lo relativo a su iglesia, combate con vehemencia la enseñanza laica"6.

En ese mismo sentido, no puede olvidarse que la propia Constitución Política de Colombia de 1886, a pesar de ser presentada "En nombre de Dios, fuente suprema de toda autoridad" y de postular que "La Religión Católica, Apostólica, Romana, es la de la Nación" ya reconocía tácitamente la existencia de otras prácticas religiosas en tanto quedaba abiertamente expresado que nadie sería "molestado por razón de sus opiniones religiosas, ni compelido por las autoridades a profesar creencias ni a observar prácticas contrarias a su conciencia" 8 . Sin embargo, el límite estaba en que solo era "permitido el ejercicio de todos los cultos que no sean contrarios a la moral cristiana ni a las leyes" .

Todo lo anterior implicó que las pretensiones laicas tuvieran en el catolicismo una fuerte resistencia que se hizo protagónica en la educación de los niños y jóvenes colombianos.

6 Manuel Murillo Toro, Mensaje al Congreso en 1874, en: Obras Selectas. citado por Alfredo Camelo, La educación en el siglo XX Bogotá: Ed. Cámara de Representantes, 1979, 383, 35.

7 Constitución Política de la República de Colombia, agosto 5 de 1886. Artículo 38. Aunque, hay que decirlo, en este mismo artículo también se expresa "que la Iglesia Católica no es ni será oficial, y conservará su independencia". Es decir, que en un mismo artículo constitucional se percibe la tensión existente: por un lado se dice cuál es la religión de la Nación, pero a renglón seguido también se intenta aclarar que esa religión de la nación no es de carácter oficial y conserva su independencia. Lo que en otras palabras significa que si bien hay una religión a la que "los Poderes públicos protegerán y harán que sea respetada como esencial elemento del orden social" ello no significa entonces que adquiera el carácter de oficial. Algo así como que está por fuera de la oficialidad conservando su autonomía, pero es defendida por la oficialidad de la que es declarada independiente.

8 Constitución Política, 1886. Artículo 39.

9 Constitución Política, 1886. Artículo 40. 
Particularmente Antioquia no fue la excepción frente a este suceso y, por ello, las instituciones formadoras - las escuelas ${ }^{10}$ - no vislumbraban en sus planes de estudio tendencias de corte laico sino que abiertamente aparecía la enseñanza de la religión y la moral católicas como asignaturas obligatorias y necesarias para la eventual instrucción de sujetos socialmente adaptados a las necesidades y preceptos de una ciudad como Medellín. Una urbe que para la época, según Melo "[...] era una ciudad en la que dominaba una ética exigente, que exigía la honradez, el cumplimiento de la palabra, el respeto al honor, y en la que la religión regulaba con provinciana rigidez la vida privada y pública de todos"11. En general, en el caso de Antioquia, al iniciar el siglo XX, la moral y la ética eran reductos vedados desde visiones laicas, las mismas que eran vistas como peligrosas; por ello los principios éticos dominantes eran fundamentalmente religiosos en el orden católico y buscaban así resolver los problemas de organización social y de convivencia entre los miembros de la comunidad.

Un caso interesante en relación con lo anterior tiene que ver con el alboroto que causó el hecho de que en el Congreso Internacional Femenino realizado en Medellín (1931) una de las damas participantes " [...] con una ignorancia desconcertante de la doctrina católica y de los principios constitucionales que nos rigen en materia de matrimonio, con un olvido irritante de las tradiciones y de costumbres de nuestra patria $[\ldots]^{\prime 12}$ sostuvo la necesidad de establecer el matrimonio civil ya que, según ella, el matrimonio católico no protegía los fueros de la mujer. Pero, lo que enardeció todavía más a las damas antioqueñas fue que buena parte del público “[...]

10 Acá nos adscribimos (CO. y AKR) a las tesis según la cual las escuelas en Occidente (y en regiones occidentalizadas) le deben su origen y continuidad a las particularidades establecidas con el Cristianismo: la canonización de un corpus de saber válido, la necesidad de expertos que aseguren y protejan ese saber, así como la institucionalización de ese tipo de administración de los saberes expertos que, por razones de celibato, ya no tendría cómo sucederse por líneas generacionales familiares, sino que, ya cada vez más, exigiría nuevos reclutamientos de los más dotados para ello. Finalmente, la relación de tensión entre creencia y saber producida en el cristianismo por la recepción de la antigüedad llevó al desarrollo de las ciencias modernas. Ella contiene el núcleo de una imagen de hombre en la que el ser humano devino en el agente de una realización de la vida metódica y responsable (2006).

11411 Jorge Orlando, Melo, Medellín: Historias y representaciones imaginadas. Medellín. Seminario: Una mirada a Medellín y al Valle de Aburrá, Memorias. (1993): 16.

12 Manifestación de protesta que hace la liga de damas católicas. Periódico El Colombiano, Medellín 9 de enero de 1931. Año XIX, 1-4. 
exteriorizaba su ignorancia o su sectarismo al recibir con estruendosos aplausos precisamente aquellos juicios atrevidos e irrespetuosos [...]" de quien, además, tildó de "[...] infructuosa y perjudicial la intervención de la iglesia católica en la instrucción religiosa y moral de la niñez y la juventud $[\ldots]^{\prime 13}$.

Se puede ver cómo la enseñanza religiosa dominante tomó gran sentido en la educación de los niños y jóvenes de la época, hasta el punto de permear, a posteriori, no solo esas dos asignaturas sino todo el conjunto de materias desarrolladas en el proceso formativo escolar en la región. Asunto crítico en tanto el campo de acción para diferentes opciones antropológicas acerca de la vida humana y la misma posibilidad de una educación no adscrita directamente a una corriente religiosa se tornaban casi imposibles ${ }^{14}$.

\section{LA EDUCACIÓN LAICA NO ES GARANTÍA DE UN ORDEN SOCIAL (CRISTIANO)}

Una gran realidad es que desde finales del siglo XIX y las primeras décadas del siglo XX, la escuela antioqueña fue constituida en un lugar propicio para instruir y moralizar a la niñez en torno al pensamiento religioso habida cuenta que las consideraciones sobre otras alternativas, para entonces, eran casi impensables. No había espacios para pensar siquiera en una educación en la que no se incluyera lo religioso. Aquí, la enseñanza de la religión, más concretamente del dogma católico, tomaba gran importancia en el contexto de la época y se constituía en el ente regulador de la sociedad. Según se decía, el objetivo de la educación era formar personas útiles a la sociedad, de buenos principios morales, éticos y religiosos y en tal dirección "cada generación de niños instruida aseguraba una secuela

13 Manifestación de protesta que hace la liga de damas católicas, 1.

14 Ello se ve con claridad en lo que Rafael Uribe Uribe planteaba en su escrito: "Reducción de salvajes" de 1907, específicamente lo que denominó el "método de reducción": "Para que sea eficaz la máquina de reducir indígenas, debe componerse de tres piezas, cada una de las cuales, obrando aisladamente no da resultado: Colonia militar, Cuerpo de intérpretes, y Misionero [...] El cuerpo de intérpretes, a cargo del misionero y de maestros civiles que les enseñasen oficios, y que podrían ser miembros de la misma tropa, se formaría [...] con niños de la tribu, obtenidos por las buenas, ya voluntariamente cedidos por los padres, o ya apelando en último caso a comprarlos [...] La experiencia de todos los pueblos y la nuestra propia, enseñan que desde el momento en que se consigue que una nación bárbara entienda la lengua de la nación cristiana que se le pone en contacto, aquélla se asimila a esta" Rafael, Uribe Uribe, Por la América del Sur. Tomo I. (Bogotá, D. E. Editorial Kelly, 1955), 160 y ss. 
subsecuente de jóvenes y adultos catequizados desde la propia primera infancia, como lo pregonaba la Biblia"15. En tal sentido una educación adecuada es la que forma moral, ética y religiosamente. Así pues, podría incluso pensarse en una educación moral y ética pero no laica en tanto desde esta perspectiva lo moral y ético lucían desconectados de lo dionisíaco.

Precisamente en este marco social y en El Colombiano (Periódico Político-Religioso (sic)) se dice que "La escuela neutra es precursora de la escuela laica, y esta es la antesala de la escuela sin Dios, y la escuela sin Dios en vivero de criminales"16. Así pues, pensar una escuela laica era pensar, sin más, en formar criminales. Y, para el caso, colocan como ejemplo a Francia al decir que "a medida que la escuela sin Dios va imponiéndose por la fuerza y el imperio de leyes irracionales o impías en la vecina República (se refieren a Francia), la criminalidad infantil aumenta de un modo espantoso" 17 . De esta forma, el principal periódico de entonces en Antioquia y "órgano del Directorio Conservador del Departamento de Antioquia" salía lanza en ristre al ataque de la escuela laica, la misma que ya se ventilaba en el exterior, y obviamente en el contexto regional más desde los discursos alternativos subversores que de las propias prácticas escolares.

En esta dirección la educación laica estaba más cerca de lo mundano que de lo celestial, de lo profano que de lo sagrado. Mientras tanto, le era delegada a las escuelas primarias, instancias encargadas de la educación de la infancia, la responsabilidad de impartir y enfatizar tanto en las ideas religiosas y como en la práctica ritualizada de dichas ideas como garantía de la formación de sujetos obedientes y como mecanismo de prevención frente al caos y los desórdenes sociales. Ello era publicitado por la dirigencia instruccionista antioqueña a partir de autores como De Guizot, por ejemplo, quien era uno de los que planteaba que "para que la instrucción primaria sea verdaderamente buena y socialmente útil, ha de ser profunda-

15 Carlos Ospina-Cruz, El mercado de las almas versus el proyecto moderno instruccionista en Antioquia, 1903-1930. Revista Historia de la Educación Colombiana. RudeColombia. Vol. 13. No. 13. (2010), 98.

16 La Escuela sin Dios. El Colombiano. Periódico Político-Religioso. Órgano del Directorio Conservador del Departamento de Antioquia. Serie XXIII, No. 223. 20 febrero de 1914, 1.

17 La Escuela sin Dios. El Colombiano..., 1. 
mente religiosa" "18; afirmaba, además, que "es menester que la educación popular sea dada y recibida en el seno de una atmósfera religiosa: que las impresiones y los hábitos religiosos la penetren por todas partes"19. Es decir, que para De Guizot el fundamento de una buena educación -a diferentes grupos sociales y en diferentes contextos- es crear un ambiente escolar altamente religioso en el que jóvenes y niños se impregnen de sus creencias y las practiquen en su diario vivir. Ni pensar, entonces en una educación laica.

En este mismo orden de ideas, De Gladstone, también útil a la argumentación de la misma dirigencia antioqueña y lanza en ristre contra cualquier pretensión laicista, propone que "todo sistema que deja a un lado la educación religiosa es un sistema peligroso" 20 . En tales circunstancias, tan siquiera pensar en una educación alejada de los adoctrinamientos religiosos conduce hacia riscos borrascosos, lo que implica, en una lógica binaria y desde esta óptica, que todos los niños deben ser educados y condicionados en la religión, pues de no hacerlo quedaría en tela de juicio la veracidad, la calidad y la seguridad del sistema educativo en tanto la formación religiosa en el contexto de la época es uno de los principales fines, pues se cree que esta garantiza en gran medida el orden social. No muy apartado de esta percepción, Uribe Arango sugiere:

"Como quiera que, lo que con mayor urgencia necesitan esos niños es la higiene moral, juzgamos que aquella instrucción debe, ante todo, ser dirigida y dada de acuerdo con los salvadores principios de la Religión Católica. Instrucción católica, primaria obligatoria, es, pues, el remedio que aconsejamos y el único que, en nuestro concepto y para el caso, ayuda a impedir que continúe avanzando la corrupción de los niños y, como consecuencia natural, aumentando el ejército del crimen en nuestro país"21.

18 Ismael Lopera, Lo que es la enseñanza sin Religión. Revista Educación Pública Antioqueña (junio de 1928), 468.

19 Ismael Lopera, Lo que es la enseñanza sin Religión..., 468.

20 Ismael Lopera, Lo que es la enseñanza sin Religión..., 468.

21 Citado por Claudia Herrera, y Tania Rubiano,. Las Infancias en imágenes cien años después de la independencia de Colombia: Iconografía e Historia. XIV Encuentro de Latinoamericanistas Espa- 
Al mismo tiempo en que se torna importante la teorización de la religión, Reaumer sugiere también la práctica de sus principios, explícitamente del Catolicismo como base del buen funcionamiento de las familias y, por ende, del Estado, afirmando que "la vida de los pueblos requiere de una educación fundada, no sobre las teorías, sino sobre realidades inmutables, sobre los principios del Cristianismo, verdadero sostén de las familias y el Estado" 22 , dándole así principalmente a la práctica de los principios que plantea el Cristianismo la calidad de reguladores y estabilizadores de las acciones que permitan que la familia y el Estado sean sostenibles y controlables. Ahora bien, la educación laica fundada per se en los principios de la ciencia no ofrecía tales garantías; mucho menos cuando todo, finalmente, era explicado en los preceptos de la fe, puntal cristiano.

Bajo esta perspectiva, la escuela antioqueña asumida como laica no podría formar niños en la obediencia cristiana, ni estratégicamente tampoco permitiría vigilar a los padres en torno a su piedad y costumbres replicadas en sus vástagos. Dejaría, eventualmente, de constituirse así la escuela en un ente de control social, donde la mala conducta de un niño fuera un pretexto legítimo, según Demia ${ }^{23}$, para ir a interrogar a los padres y comprobar si saben el catecismo y las oraciones y si están resueltos a desarraigar los vicios de sus hijos.

Lo que hasta este punto se plantea es claro: en la educación de los niños y jóvenes antioqueños, en las primeras décadas del siglo XX, no había espacio para pensar desde posturas laicas; debía ser profundamente religiosa y, en coherencia con ello, la Arquidiócesis de Antioquia asumió un papel regulador en lo que a asuntos educativos gubernamentales concierne. Fue así que para 1913 se constituye como un derecho del Señor Obispo el poder inspeccionar el enfoque moral y religioso que se estaba impartiendo en las escuelas y colegios de Medellín y Antioquia. De tal forma, los diques hacia una posible educación laica se hacían cada vez más altos.

23 Citado por Michael Foucault, Vigilar y Castigar. (Buenos Aires, Argentina: Siglo XXI Ed. 2002), 215. 


\subsection{LA INFLUENCIA DIRECTA DEL OBISPO SOBRE LOS MAESTROS}

Este derecho del señor Obispo implicaba mucho más que simplemente vigilar a la escuela y la educación que se estaba impartiendo en los centros educativos para detectar posibles gérmenes peligrosos, entiéndase laicos o de otras tendencias religiosas (para generalizar aquí el problema). Podía incidir en el despido de algún profesor en caso de considerarlo una amenaza para las buenas costumbres y para la fe de sus discípulos; de paso, también podía prohibir el uso de cartillas, libros y de cualquier instrumento educativo que se considerara peligroso para la iglesia Católica.

Así, el Obispo contaba con tanto o más poder que la Secretaría del ramo en este Departamento y con mayor poder de decisión en las escuelas que los mismos rectores y directores. Con tal situación, además, los textos escolares se direccionaban más a la formación de sujetos morales que de sujetos intelectuales al servicio de la vida y la sociedad; se imponía, pues, una estrategia para homogenizar a los jóvenes en las doctrinas y dogmas de la iglesia Católica, Apostólica y Romana en una suerte de lucha frontal con otras formas posibles de ver y actuar en el mundo. En palabras de Foucault, lo que se pretendía de forma implícita era "ejercer sobre ellos una presión constante para que se sometan todos al mismo modelo, para que estén obligados todos juntos a la subordinación, a la docilidad [...] y a la exacta práctica de los deberes y de todas las partes de la disciplina. Para que todos se asemejen" ${ }^{24}$. Modelo pastoral homogeneizador que desde la perspectiva laica, preocupantemente, aún no era visible.

No obstante, y si bien la iglesia Católica tomaba un papel protagónico creciente en la educación de la niñez y la juventud antioqueña, la responsabilidad directa estaba delegada a los maestros oficiales quienes debían dar instrucción religiosa, formación en valores, virtudes y principios morales a cada uno de sus discípulos. El temor a que los maestros no cumplieran las exigencias doctrinarias y se dejaran llevar por presuntas prácticas laicas estaba latente. Por tal razón, la Diócesis antioqueña se esmeró en instruirlos y orientarlos en su filantrópica labor.

24 Michael Foucault, Vigilar y Castigar..., 187. 
En efecto, todas las instituciones educativas, públicas y privadas, debían incluir la enseñanza religiosa confesional dentro de sus planes de estudio, de lo contrario serían censuradas y denunciadas por incumplir dicha norma con todas las consecuencias sociales que esto podría significar para quienes fueron públicamente señalados. Así pues, se dictaminaba: "úrjase de tal manera la obligación del estudio de la Religión en los colegios públicos y privados, que por ningún pretexto puedan los maestros eximir de él a sus alumnos. Los respectivos Ordinarios podrán, si se omite este estudio, declarar laicos dichos establecimientos y denunciarlos como tales ante el pueblo" 25 .

Era de tal magnitud el sistema de control social a los maestros que, además de que se señalaba la importancia de que los docentes fueran católicos apostólicos y romanos, todavía se iba más adelante y se dividían las escuelas en dos categorías; la primera eran las escuelas católicas así consideradas como templos sagrados de conocimiento, los cuales educarían en un camino para la vida, poniendo a Jesús el mártir como ejemplo a seguir. Y, la otra parte en la que se dividen las escuelas, es las de carácter laico, las cuales también serían templos, pero en los que no se instruye sino que, por el contrario, se destruye, con una educación para el señor de las tinieblas, según se decía. A su vez, también se hace la misma caracterización con los profesores: los católicos serían los sacerdotes de Jesús, y los profesores laicos serían los sacerdotes del ángel rebelde o del demonio ${ }^{26}$.

Como se puede ver, a diferencia de la corriente laica regional en la educación, la corriente doctrinaria religiosa sí tenía medios de comunicación constantes para llegar a los educadores y propagar su verdad. Es así que dicha orientación fue publicada en la revista Instrucción Pública Antioqueña, donde E. Palacio, Obispo de Antioquia en 1913, expone que "El maestro, que debe ser el buen labrador o cultivador de esa tierra que es el joven, debe sembrar la semilla del bien y de la virtud"27, lo que implica un lla-

25 Diderot, Reglamento para las escuelas, en Revista Educación Pública Antioqueña. Medellín, No. 69. Serie V. (Febrero de 1928): 534.

26 Thomsom, Las escuelas y los maestros, en: Estudios Pedagógicos(Medellín, julio 10 de 1913). Serie 1, No. 2.

27 Eduardo Palacio, “Instrucción”, en: Instrucción Pública Antioqueña. No. (octubre de 1913), 33. 
mado a generar un proceso vital en los estudiantes, encaminándolos a ser buenos ciudadanos y firmes católicos. Es de esta forma como el maestro, aquel labrador de la juventud, empieza a ser valorado en la primera década del siglo XX siempre y cuando representase un buen ejemplo de vida caracterizado en valores tanto dentro como fuera de su práctica educativa. Entiéndase, valores alejados de cualquier pretensión laica.

Visto así, el docente (al que más le vale declararse antilaico) es llamado a alejar a sus estudiantes de todo aquello que sea considerado una tentación o que esté mal visto ante los ojos de Dios y de la sociedad, permeándolos en todo momento con la verdad católica, la práctica de las virtudes morales y la piedad cristiana. Dicho argumento lo analiza el historiador Humberto Quiceno cuando explica que, para entonces:

"La población ha de ser educada en un saber difundido por el Estado, para que la sustraiga de la miseria, la enfermedad, las pasiones y el crimen. La gente educada es aquella que ha recibido una instrucción. La pasión y el crimen se muestran más en los ignorantes según la estadística de la época: la estadística indica el blanco a moralizar y civilizar los ignorantes y en general toda la población" 28 .

En efecto, la educación estaba permeada por dos frentes importantes de la sociedad de la época los cuales se articulaban de tal forma que ejercían un control casi total sobre el individuo. Por un lado, se encontraba la iglesia Católica, interesada por formar hombres moralmente aceptables y encaminados dentro de los lineamientos del Catolicismo y, por el otro, el Estado preocupado por educar futuros ciudadanos de bien, ya que la falta de instrucción incentivaría tendencias anarquistas, vandálicas o criminales. En medio, o como grilla de articulación entre esas dos tendencias, estaba el maestro, que no solo debía formar en el bien, sino frenar a toda costa esa potencialidad que le otorgaba la ignorancia al mal.

28 Humberto Quiceno Castrillón, Pedagogía católica y escuela activa en Colombia (1900-1935). Bogotá: Ediciones Foro Nacional por Colombia.(1988), 128. 
En este orden de ideas, y bajo la lógica de formar un ser integral, el maestro antioqueño además de enseñar a sus discípulos a leer, escribir y acerca de otras materias, debía fundamentalmente educarlos bajo los cánones de la religión Católica para ser considerado un verdadero pedagogo, es decir, una "persona encargada de criar o EDUCAR (sic) a un niño" 29 , de formar su carácter para así hacerlo miembro útil y activo de la sociedad, capaz de aportar, participar, ayudar a sus compañeros, decidir lo que es conveniente y generar un ambiente propicio para la convivencia. En efcto, pedagogos por fuera de una confesión religiosa no eran posibles.

Por tales razones, la educación pública antioqueña era organizada de conformidad con la religión Católica y era deber del maestro velar por el objetivo principal de dicha educación, dándole a conocer a sus estudiantes los orígenes del cristianismo, la vida de Cristo, sus enseñanzas, la realidad de un Dios que los ama; se trataba de inducirlos a la fe y a seguir los caminos y ejemplos de las virtudes practicadas por las grandes figuras de la Iglesia. Hablamos, entonces, de una educación, doctrinaria, la misma que debía ser impartida por maestros convencidos, o aparentadores de su convencimiento so pena de no ser permitidos en la lista oficial. Aquí, a pesar de algunos focos alternativos, es claro que el sistema instruccionista oficial opera, con la anuencia estatal, contra la línea laica.

\subsection{LA “NATURALEZA CRISTIANA" DEL ANTIOQUEÑO COMO TAREA EDUCATIVA}

Tenemos, pues, un magisterio estatal que tenía que asumir su tarea con seriedad, ya desde el hogar, o desde la escuela, mostrando testimonios de buen vivir, respeto, obediencia y demás virtudes, pero sobre todo, siendo modelo de vida para los jóvenes y niños de la época y del contexto en que se estaba, y no dando, ni por un momento, asomos laicos.

Aquí es importante resaltar la importancia del contexto como un gran obstáculo para el avance de las opciones laicas en el campo instruccionista, porque tal vez en otras regiones del país -y del continente- la autoridad de la religión no ha sido tan arraigada como en Antioquia, pues este departa-

29 Eduardo Palacio, Instrucción que el obispo hace a los directores y maestros de escuelas y colegios de su Diócesis”, en: Instrucción Pública Antioqueña. No. 50. (octubre de 1913), 34. 
mento se ha caracterizado a lo largo de su historia por la fiel creencia de las familias en los principios dictaminados por el Catolicismo hasta el punto de que se ha dicho que "la naturaleza (sic) de los antioqueños era la de ser instruidos en la divina redención ${ }^{30}$.

Como lo explica Fortuny, citado por Ríos Molina, analizando históricamente el problema religioso en el Urabá Antioqueño:

"La construcción de las identidades religiosas está íntimamente relacionada no solo con el nuevo grupo religioso al que se integra el individuo, sino también con su origen familiar, el tipo de sociedad, región cultural y su posición social y económica en la sociedad con respecto a otros sectores" 31 .

De acuerdo con este planteamiento de Fortuny el origen familiar determina en gran medida las identidades religiosas del individuo. $\mathrm{Y}$ si a esto le agregamos lo sugerido por Donzelot, en el sentido de ver a la familia como sujeto y objeto de gobierno y, en esta segunda posición, siendo sometida a relaciones de dependencia frente al Estado ${ }^{32}$, entonces también se entiende la justificación contextual de los padres que enviaban a sus hijos a escuelas en cuya puerta estuviese escrito: "Aquí no se enseña religión" temerosos de que pudieran ser llevados a los tribunales ${ }^{33}$. Esta idea la sustenta De Víctor Hugo en el texto "Lo que es la enseñanza sin religión" responsabilizando a los padres para que elijieran las escuelas donde serían formados sus hijos, sin dar muchas opciones de sortear el tipo de educación que les iba a ser impartida puesto que el dogma Católico era considerado por el Estado colombiano como la religión oficial del país y, por ende, como la que debía ser profesada en todas las escuelas públicas y privadas de entonces.

Como se ha venido diciendo, la educación moral y religiosa es un aspecto

30 Carlos Ospina-Cruz, El mercado de las almas..., 96.

31 Citado en Andrés Ríos Molina (2003). Identidad y religión en la colonización del Urabá Antioqueño, en Tabula Rasa N 1 (en línea). Recuperado el 24 de abril de 2011 en http:/ /www.revistatabularasa. org/numero_uno/Mospina.pdf-

32 Donzelot, Jacques. La policía de las familias. Valencia. Pre-Textos, 1979.

33 De Víctor Hugo, Lo que es la enseñanza sin religión. Revista Educación Pública Antioqueña (Junio de 1928). 469. 
que se enfatizó en gran medida en los textos y currículos de las escuelas colombianas en la primera mitad del siglo XX. En las revistas de Educación Antioqueña publicadas entre 1913 y 1940 se hacían explícitos varios Decretos Nacionales que se referían al tema, lo que sugiere que las escuelas antioqueñas se adherían firmemente a ellos. Ante este panorama, la educación laica debía vérselas no solo con las tradiciones, las creencias y los dogmas sino también con la fuerza del aparato estatal.

Y era en el contexto de la crisis en la que se desenvolvía la labor de los institutores a principios del siglo XX en Antioquia -crisis arrastrada desde el siglo XIX y persistente para los albores de la reforma instruccionista de 1903- que la iglesia Católica se arrogaba para sí la potestad de clasificar dos tipos mutuamente excluyentes de educacionistas (entiéndase maestros, institutores): los legos -laicos- y aquellos de los institutos religiosos.

Para la iglesia con sede en Roma, estos últimos llevaban “inmensa ventaja sobre el gremio laical, por la razón obvia y potísima de que desempeñan sus funciones por vocación y los otros por interés"34. Es decir, quienes trabajaban por vocación eran los apóstoles sacrificados del evangelio, pertenecían generalmente a alguna congregación y obraban en bien de la causa católica, y su interés estaba por encima de sí mismos en tanto buscaban ayudar a la salvación de los degenerados. Mientras que los educacionistas que lo hacían por un interés menos trascendental -entiéndase trabajo, desempleo, falta de oportunidades, etc.- no aparecían como los abanderados naturales de la iglesia sino de las intenciones gobiernistas. Así pues, quienes trabajaban en esta última situación lo hacían para la reforma y el cambio y, en contravía, quienes pertenecían a la iglesia estaban siendo constantemente "concientizados", para no plegarse a las borrascas modernizadoras. Al parecer, el bloque fuerte y "respetable" de los educacionistas de las instituciones religiosas tenían clara su misión, por encima de cualquier otra oferta mundana; mientras los laicos sufrían de la falta de "miramientos, de consideraciones y de deferencia" 35 como las que merecía un gremio como el instruccionista. Por eso, se pretendía dejar sentado que

34 “Educación”. El Lábaro. Órgano oficial de la Arquidiócesis de Medellín, No. 18 (diciembre de 1905), 276.

35 “Educación”. El Lábaro..., 276. 
la labor del maestro era

"[...] adaptar los conocimientos de las generaciones pasadas, conseguidos en siglos de gestación, a las generaciones presentes y venideras, perfeccionándolos en armonía con las leyes del progreso y con las necesidades de los pueblos, a fin de que la educación integral satisfaga no solo a las exigencias materiales y físicas de la vida ordinaria del alumno, en todo orden de ocupaciones, sino a las aficiones del espíritu, a la expansión de los sentimientos y creencias, al desenvolvimiento de sus facultades conscientes, conforme con su destino en la tierra y su fin último que es el cielo" $"$.

En síntesis, para la educación antioqueña de principios del siglo XX, la religión y la moral son vistas como ejes articuladores en los planes de estudio y en las instrucciones dadas a los jóvenes y niños. Bajo esta mirada muchas acciones realizadas por estos, eran consideradas como una falta a la moral e incluso como una enfermedad cercana a los virus laicos, lo que dejó entrever que pese a la importancia y énfasis de los lineamientos que regían la educación de la época, surgieron un conjunto de dificultades y contradicciones en la práctica instruccionista como tal.

\section{LA ESCUElA ACTIVA ${ }^{37}$ COMO EVENTUAL PUERTA A LA EDUCACIÓN LAICA}

Es importante señalar, como lo hace Martha Cecilia Herrera en el libro: "Modernización y Escuela Nueva en Colombia", que el movimiento esco-

36 J. Henao, Apertura de la Conferencia Pedagógica, 15 de diciembre de 1909, en: Instrucción Pública Antioqueña. Imprenta Departamental de Antioquia. No. 23 (enero de 1910), 114.

37 El movimiento de escuela activa o pedagogía activa, también identificado con expresiones como escuela nueva (école nouvelle), educación nueva (éducation nouvelle), educación activa (éducation active), pedagogía reformista (Reformpädagogik) o educación progresista (progressive education), representa uno de los momentos más ricos y productivos en la historia de la pedagogía y de la educación tanto a nivel mundial como nacional. En Colombia la pedagogía activa se generalizó a finales de los 20 y mediados de los 30 y en su seno se desarrollaron numerosas ideas y planteamientos pedagógicos novedosos que redundaron en propuestas de reforma y proyectos teórico-prácticos. La importancia de este movimiento de comienzos del siglo XX radica en haber tratado de romper con la concepción tradicionalista, pasiva y jerárquico-autoritaria de la educación, en haber asumido una posición crítica frente a la "vieja escuela" (denominada también escuela tradicional) y en haber propuesto una nueva manera de mirar la infancia y su educación, basada ahora en el respeto y preocupación por el niño y en el fomento de su formación mediante la actividad. 
lanovista en Colombia tuvo tres variantes, a saber: una variante psicologista liberal y laica ${ }^{38}$, representada por Agustín Nieto Caballero (1889-1975) y su discípulo Gabriel Anzola Gómez (1904-1994); una variante psicologista católica, representada por Miguel Jiménez López (1886-1965), Rafael Bernal Jiménez (1898-1972) y Eduardo Vasco, y una variante sociologista laica constituida, más por intelectuales que por pedagogos, dentro de los que se cuentan José Francisco Socarrás (1906-1996), Luis López de Mesa (18841967), Germán Arciniegas, Darío Echandía y Gerardo Molina.

Es decir, que a partir de la primera década del siglo XX se comenzó a pensar, desde varios frentes como el científico, el político, el educativo, en la posibilidad de construir una pedagogía oficial que no fuera católica, ya que las posturas sobre la cultura y la sociedad que defendía la Iglesia, tenían como característica principal el oponerse a ideas que apoyaran el sostenimiento, la defensa y la reproducción de la sociedad industrial que se venía desarrollando en ese entonces - prospecciones no solo de los liberales ${ }^{39}$ sino también de algunos conservadores que bien podrían ser denominados liberales en economía-. No obstante, en el caso de Medellín y otras zonas de Antioquia, las comunidades religiosas apoyaron políticas de intelectuales conservadores en la constitución de instituciones de educación centradas en la formación de artesanos.

\subsection{EsCUELA ACTIVA Y RELIGIÓN CATÓliCA ARTICULADAS EN ANTIOQUIA}

Las propuestas acerca de la Escuela Activa y la religión católica lograban, de un lado, articularse de manera interesante en el contexto antioqueño; pero, de otro lado, también preocupaban a algunos sectores que veían en

38 Nieto Caballero y en la perspectiva del enfoque histórico sobre la educación laica en Colombia planteaba, en tal sentido que "al analizar una escuela debemos desentrañar cuál es su espíritu [...] dogmático [...] o democrático; existen escuelas donde es preciso obedecer ciegamente y escuelas donde se permite pensar y actuar [...] recordad constantemente que enseñáis más con vuestro ejemplo que con vuestra palabra, o mejor, que solo enseñáis con vuestras palabras cuando ellas se ajustan a vuestros actos (Agustín Nieto Caballero, Los Maestros. (Bogotá. Editorial Antares Ltda. 1963), 49-54).

39 Para autores como Verdugo Moreno $(2004$, p. 6) "el modelo educativo liberal situó al maestro junto a su alumno, y no al cura o al gamonal como uno de los ejes de la educación, la que se centraliza ubicando al maestro en el corazón de la nacionalidad, en relación directa con un Estado del que emanaban las directrices para hacer más eficiente su práctica pedagógica" (Verdugo Moreno, P.C. Educación y Política en el siglo XIX: Los modelos laico-liberal y católico-conservador. Revista Historia de la Educación Colombiana. No. 6-7, (2004), 81. 
estas nuevas propuestas algunos avances de la educación laica en el Departamento.

En cuanto a la primera parte, la Escuela Activa permitía la movilidad de los alumnos, las excursiones por fuera de los claustros e impulsar los intereses infantiles en pos de las actividades (más dinámicas y de mayor movimiento corporal). Así mismo, ayudaba a las propuestas catequéticas católicas, logrando insertarse como justificación de un interés casi natural en los alumnos para la búsqueda de obras piadosas y cumplir así con los preceptos establecidos.

En principio, no se percibía, entonces, una lucha abierta y sin cuartel por el poder metodológico y por los nuevos contenidos, sino que se ponían -adaptaban- los contenidos clericales bajo presunciones e intereses escolanovistas en las nuevas modalidades metodológicas. En tales circunstancias, resultaba revitalizada la doctrina católica, en tanto se ubicaba en nuevas dinámicas que la hacían ver renovada y capaz de adaptarse, además, a las modernizadas posturas pedagógicas.

No obstante, y en relación con la segunda perspectiva, se presentaban casos en los que se planteaba que la Escuela Activa se oponía a la denominada escuela tradicional: "[...] oponemos nosotros la escuela dinámica y cubiótica $^{40}$ (sic) que robustece el psiquismo en un ambiente de paz, que lo hace crecer de dentro (sic) hacia afuera y lo vincula a la ley cósmica, conciliando lo espiritual y lo físico, y templando las fuerzas vitales, protectoras, defensivas y reactivas a tono con los agentes naturales" ${ }^{41}$. Y cuando aquí se decía eubiótica se hacía referencia a una alimentación sana y equilibrada; a una sexualidad sana, sin miedos ni tabúes; al ejercicio físico regular y a salidas al campo o a la montaña (estas para los que vivían en las ciudades); y no abusar del tabaco ni de las bebidas alcohólicas.

Curiosamente, aunque aquí se piensa en la Escuela Activa como una nueva opción frente a la tradición, también se la considera como una apuesta por

40 Más adelante, en la misma fuente, se aclara que no es cubiótica sino enbiótica la palabra que se quiso utilizar.

41 Zuluaga y A. Gutiérrez, La cuestión cultural en Colombia. "Esto matará aquello". Capítulo III, en: Revista Claridad. Año 1, No. 28 (septiembre de 1930), 1223. 
una sexualidad sana sin miedos ni tabúes y se morigera levemente el uso del tabaco y del alcohol, aspectos que colocaban a esa Escuela Activa posiblemente más cercana a una educación laica que a los férreos controles sobre esos factores aplicados desde la doctrina cristiana de entonces en esta región del país.

Todavía más, en forma novedosa, esta inclusión de la actividad en lo educativo a instancias de la Escuela Activa no significaba formar para el trabajo, sino para poner en contacto al sujeto con la naturaleza y con las fuerzas cósmicas. Se esperaba que una escuela como esta lograría, en principio, el respeto a las individualidades, que los sujetos pudieran crecer desde su interior hacia afuera y no a la inversa como se pretendía, entregando todo, para que el sujeto creciera interiormente pero sin tener en cuenta su interior; esta expresión del interior lograría magníficamente la conexión de los sujetos con el universo, y las energías creadoras de cada uno saldrían a flote. He aquí una escuela conectada con los sujetos, con la naturaleza humana en su prodigiosa energía y con el cosmos creativo. Seguida de un control de los impulsos y de una ordenación del mundo interior, estaría una moral cósmico-religiosa sin necesariamente caer en un panteísmo. Claramente, los anteriores planteamientos abrían ciertamente la puerta a un nuevo tipo de visión del ser humano y a un enfoque diferente del proceso formativo, ahora no necesariamente apegado a una doctrina ética y moral predeterminada.

En verdad, para usar aquí una expresión bien conocida, se estaba apostando por una Escuela Activa, con pretensiones abiertas, más en el terreno de lo naturalista que, incluso, de la propia formación para el trabajo, intención creciente en Antioquia desde la promulgación de la Ley 39 de 1903. Se hablaba ahora de una escuela al aire libre, en donde se otorgara mayor importancia al cuerpo y, por lo tanto, al ejercicio físico; una escuela que considerara las salidas del salón de clase como parte del proceso de enseñanza y que, además, trabajara para disminuir los vicios (alcohol y tabaco), aunque esto último sonara a contrasentido porque los mismos maestros eran pagados con el dinero proveniente de las ventas departamentales de licor, y hasta con licor en especie, lo cual de suyo ya suena a despropósito. 
Y aunque una de las pretensiones de la Escuela Activa estaba centrada en propiciar justamente una educación laica, resultaba que, en consecuencia, el enfoque religioso naturalista no era lo que se impulsaba efectivamente. Por el contrario, sentenciaban los eruditos, "[...] lo dicho no implica que los educadores no puedan, no deban formar el ambiente religioso propio de la religión cristiana"42. Ello quedaba fundamentado en que la religión católica era por sí misma y por derecho divino, la luz que podía iluminar el aprendizaje sobre todas las ciencias, era el faro que guiaba pero, como en un ejercicio físico, la luz no podía iluminarse a sí misma. La doctrina católica tenía una doctrina tan sabia e intensa que arrojaba clara y abundante luz en todas las ciencias y en todas las artes ${ }^{43}$.

Era claro que una escuela laica, puesta en tensión frente a la escuela existente e históricamente arraigada, no tenía las puertas abiertas de par en par, así sin más. En algunas ocasiones era atacada "en un arranque de xenofobia descaminada" 44 como un factor extraño, cuando ella no solo carecía de sello de novedad propiamente hablando, sino que era de todas aquellas latitudes en las cuales la razón bien dirigida era reina y señora de los destinos de la colectividad ${ }^{45}$. Era pues una Escuela Activa cuyos principios se esperaba que pudieran ser aplicados en Antioquia, pero con las condiciones regionales. Puede así llegarse a plantear la existencia de una nueva escuela en Antioquia con algunos principios de la Escuela Activa, aunque no necesariamente semejante, o igual en todo sentido, a otras llamadas escuelas activas en otros lugares del mundo, donde pudieran haberse llegado a establecer con anterioridad ${ }^{46}$.

Aquí, la estrecha conexión esperada de la Escuela Activa con el medio, y los resultados no deterministas de tal fusión, era una situación que parecía estar clara. "Es preciso repetirlo: la Escuela Activa vale por sí misma, por

42 Zuluaga y A. Gutiérrez, La cuestión cultural en Colombia..., 1223.

43 Zuluaga y A. Gutiérrez, La cuestión cultural en Colombia..., 1223.

44 Zuluaga y A. Gutiérrez, La cuestión cultural en Colombia..., 1224.

45 Zuluaga y A. Gutiérrez, La cuestión cultural en Colombia..., 1224.

46 Zuluaga y A. Gutiérrez coloca como ejemplo de esta situación, la forma en la que se había materializado la Escuela Activa en el Gimnasio Moderno en Bogotá, o la forma en que Santo Tomás la entrañaba en sus doctrinas. 
su virtud insíta ${ }^{47}$ (sic), por su facilidad de adaptación a todos los medios pues busca reintegrar el hombre a su ambiente, y por este trámite sencillo y expedito, al ambiente universal" ${ }^{48}$. Lo que surgía nuevamente era la inquietud por la posible separación del hombre con relación a su medio, tal vez por el ensimismamiento doctrinal, situación que parecía ser una consecuencia de la escuela existente, y de allí la manifestación expresa para reintegrarlo al ambiente y, por ese mismo camino, hacerlo parte del conglomerado universal del que había estado, supuestamente, separado. En tal sentido, se decía que
"La Escuela Activa pide el contacto inmediato en la maravilla del mundo, cuyos seres, cuyos objetos, cuyas manifestaciones son caminos abiertos a la sabiduría, al amor y a la belleza, siempre que haya sentidos suficientemente aptos y facultades anímicas suficientemente dispuestas para entrar en franca comunión con ellas" $"$.

No se trataba pues de poner a trabajar o a rendir cuentas al ser humano sino de conectarlo cósmicamente. No se trataba tampoco, según se desprende de lo planteado, de conducirlo por un único universo ideológico sino de mostrarle opciones del vasto universo humano y natural. Esa posibilidad de que se permitiera al ser humano hacer parte en su formación de adentro hacia afuera, era la que también le debería permitir que huyera de la parálisis mental y material, y así pudiera descubrirse a sí mismo en el libre juego de sus poderes físicos y espirituales ${ }^{50}$. Quedaba ubicado el estudiante, de esta forma, "[...] en ese plano de eficacia en que ninguna energía fracasa y todas las fuerzas adquieren plenitud" 51 .

La Escuela Activa que se promulgaba aquí era, entonces, el escenario ideal en el cual podría darse un tipo de formación que facilitara el surgimiento de sujetos potencialmente más heterogéneos y únicos. Sujetos plenos de

47 Del latín insitus, participio pasado de inserěre, plantar, inculcar. Propio y connatural a algo y como nacido en ello (Diccionario de la Lengua Española, Real Academia Española - RAE).

13048 Zuluaga y A. Gutiérrez, La cuestión cultural en Colombia..., 1224.

49 Zuluaga y A. Gutiérrez, La cuestión cultural en Colombia..., 1224.

50 Zuluaga y A. Gutiérrez, La cuestión cultural en Colombia..., 1224.

51 Zuluaga y A. Gutiérrez, La cuestión cultural en Colombia..., 1224. 
vitalidad y en uso eficaz de sus capacidades humanas. Y era posiblemente en este sentido que se podía entender que la escuela pasaba a estar centrada en el niño y no en el maestro y el tablero, como usualmente ocurría, porque el niño era "el órgano vivo de la escuela y no el institutor" ${ }^{2}$. He aquí, entonces, que se hablaba de un tipo de educación en donde lo religioso no era lo prioritario porque había un libre juego de sus poderes físicos y espirituales y en donde todas las fuerzas, al menos idealmente, adquieren plenitud.

De allí el papel que entra a cumplir la educación como ese medio entre el individuo y la colectividad y como espacio para el fomento de lo heredado y su realización como criterio de progreso y de avance. La "naturaleza" del niño se desocializa de una manera radical y, en consecuencia, se biologiza. La educación y el individuo llegan hasta donde el imperativo biológico lo permite; acá ni el deseo ni lo cultural son tenidos en cuenta. Se trata ahora de pensar en una educación que se enmarque bajo esas otras condiciones y que siga el ritmo de la naturaleza: "Por otra parte, el organismo humano tiene también su ritmo evolutivo, sus necesidades y sus intereses, que son harto diferentes en cada etapa de desarrollo individual. Observadlos con atención, tenerlos en cuenta a cada edad, proceder en las disciplinas formadoras al compás con las sabias cadencias de la naturaleza, es también aplicar a la educación el procedimiento de la vida. Esta quiere que no se festinen sus etapas, que todo cambio llegue en su día y a su hora; y así debe proceder la educación” (Jiménez López, 1928: 12). Cita a pie de página

\subsection{Félix Restrepo: una escuela para la Vida DENTRo de UN ORdeN RELIGIOSO CRISTIANO (LA ESCUELA MANJONIANA)}

Sin embargo, las resistencias preexistentes no daban el brazo a torcer. A modo de ejemplo, se esbozaba que no solo se trataba de aprovechar la Escuela Activa para entrar en contacto con la naturaleza, sino también para seguir buscando a Dios: "Por eso amigos míos, diafanizar (sic) los instrumentos de los sentidos para que sean fieles vehículos de las maravillas de Dios y ministros acuciosos de las potencias psíquicas, es obra primor-

52 Zuluaga y A. Gutiérrez, La cuestión cultural en Colombia..., 1224. 
dialísima de la Escuela Activa"53. Así pues, en términos pedagógicos la realidad no debía ser simplemente copiada por el alumno, sino asimilada en el "orden correcto" dado por Dios.

De otro lado, los jesuitas, como factor importante de la denominada tradición antioqueña, veían con preocupación cómo se podía avanzar en la práctica escolanovista eliminando de tajo los aportes tradicionales, muchos de los cuales habían sido precisamente desde el punto de vista religioso. Criticando, por ejemplo, en 1928 a Jiménez López, para entonces Ministro de Educación, se le reconocía que se hubiera referido a "las tendencias actuales de la educación primaria" valiéndose para ello de una revisión “[...] a la organización escolar y los nuevos métodos empleados hoy por algunas de las más prosperas naciones: Alemania, Dinamarca, Inglaterra, Suiza, Francia y Estados Unidos" 54 .

La inquietud jesuita no estaba en que se hablara de un nuevo tipo de educación en el país, para que se pudiera prosperar como ya lo habían hecho otras naciones, sino en que se desvirtuaran totalmente los aportes de la educación tradicional con respecto a la nueva estructura que se quería implementar en Colombia. Lo antiguo no había sido malo y, por lo tanto, debía, casi que por derecho, formar parte de lo nuevo; esa era una suerte de conclusión Jesuita ${ }^{55}$. En el texto de Jiménez López, decía la intelectualidad jesuita, "[...] verán como en Francia el laiscismo (sic) oficial es esencialmente rutinario, bien que no faltan iniciativas privadas (entre otras, las de los religiosos de que no habla el autor) merced a las cuales la educación francesa ocupa siempre un puesto de honor en el mundo" "56. Este ejemplo, entre los de otros países que analizaba Jiménez López, era especialmente llamativo porque en él, desde la perspectiva jesuita, se enfatizaba en que el sitial de honor de Francia en el concierto educativo no se debía principalmente al "laiscismo oficial" sino a la no bien ponderada y reconocida educación religiosa.

54 Félix. S. J Restrepo. La escuela y la vida, en Educación Pública Antioqueña. No 76 (septiembre de 1928); 609.

55 Félix. S. J. Restrepo, La escuela y la vida..., 609.

56 Félix. S. J Restrepo. La escuela y la vida..., 609-610. 
En otra vertiente analítica, el jesuita Restrepo resaltaba, continuando con la lectura de Jiménez López, a los Estados Unidos, en donde según él iba "[...] triunfando la tendencia pragmatista con todas sus ventajas y con todos sus inconvenientes, que hacen de ese pueblo un formidable trabajador en lo material, pero también un formidable decadente en lo moral" ${ }^{57}$. En la situación norteamericana se había dejado de lado la formación religiosa y priorizado la formación social y para el trabajo, lo cual no dejaba de ser un asunto crítico para un jesuita teólogo y estudioso del sistema instruccionista. Según Restrepo ${ }^{58}$, Jiménez López pecaba de ingenuidad al esperar que la educación a la nueva usanza fuera a ser la panacea de todos los males que aquejaban a la humanidad ${ }^{59}$. Y le reprochaba, por ejemplo, que utilizara para sus disertaciones sobre la nueva educación a Claparede, Montessori, Dewey y Kerchensteiner, pero no tuviera en cuenta a "Andrés Manjón, verdadero y genial inventor de la Escuela Activa de España"60.

"Las Escuelas Manjonianas, tan poco conocidas entre nosotros, son las que verdaderamente han desarrollado el ideal de la Escuela Activa" se planteaba desde la orilla de los Jesuitas ${ }^{61}$. Los puntos de encuentro que servían de enlace con la Escuela Activa eran los conceptos de "las Escuela Activas, los Centros de Interés y el Ambiente" ${ }^{92}$. Estas posiciones que intersecaban estas dos posturas se hallaban "reunidas en las escuelas del Ave María"63. La posible resistencia preexistente a los planteamientos de la Escuela Activa en un departamento como Antioquia, con mayoría católica y predominio del catolicismo en los direccionamientos escolares, se veía ahora con

57 Félix. S. J. Restrepo, La escuela y la vida..., 610.

58 Félix Restrepo, S. J., (Medellín, 1887 - Bogotá, 1965), Padre jesuita antioqueño, escritor, humanista y pedagogo. Doctorado en Filosofía en Holanda (1911), en teología en España (1920) y en pedagogía en Alemania (1923). En pugna con los liberales "que han estado siempre proclamando el fracaso de la educación católica de los colombianos” (1928, p. 608), Restrepo analizaba, en la Revista Educación Antioqueña, el texto del entonces Ministro de Educación, Miguel Jiménez, denominado "La escuela y la vida". Pretendía desvirtuar a quienes lo "han afiliado sin más ni más [...] entre los enemigos de nuestra educación tradicional". Le inquietaba que un ministro impulsor de la reforma educativa en ciernes desde 1903 fuera colocado también como enemigo de la escuela "antigua", en donde Restrepo operaba como socio activo.

59 Félix. S. J. Restrepo, La escuela y la vida..., 610.

60 Félix. S. J. Restrepo, La escuela y la vida..., 610.

61 P. J. Olano García, Escuelas Manjonianas..., 433.

62 P. J Olano García, Escuelas Manjonianas..., 433.

63 P. J Olano García, Escuelas Manjonianas..., 433. 
una situación que ofrecía calma. La Escuela Activa era, supuestamente, la misma escuela del Ave María fundada por Manjón. En ese orden de ideas, los postulados escolanovistas ya los habían planteado los católicos españoles, y lo que se debería hacer ahora en Antioquia era recuperar ese tiempo perdido y aceptar la Escuela Activa como un acomodamiento de la pedagogía católica, a casi medio siglo después de haberse puesto en marcha en el Viejo Continente.

En otras palabras, el bagaje histórico de la Escuela Activa que se buscaba enaltecer para Antioquia, estaba basado en principios cristianos. No era tan nueva, en todo el sentido de la palabra (perdiendo así parte de la carga pro-resistencia de lo diferente), y tenía cimientos en lo cristiano. Valga decir que ya había sido experimentada en Europa por los pedagogos católicos y era la tendencia manjoniana la que se presentaba como aquella que, verdaderamente, había desarrollado la Escuela Activa: "Las orientaciones pedagógicas señaladas por ellas (las Escuelas Manjonianas) son las que más convienen a nuestro medio" ${ }^{64}$, decían las voces jesuitas.

Había un llamado a fortalecer el escolanovismo, pero con un sesgo evidente, mirando el ejemplo de las Escuelas Manjonianas. "Deberíamos dirigir los ojos a las escuelas del Ave María, en donde encontraremos el torrente de agua cristalina para fertilizar nuestro campo educativo" ${ }^{65}$, se pregonaba. Le quedaba dicha misión al pedagogo de los “[...] quilates que es el Sr. Cadavid Restrepo, director de Educación Pública, quien afortunadamente se halla obsesionado por introducir entre nosotros la Escuela Activa"66. Esta invitación, publicada en la misma Revista de Educación Pública, oficina de la cual era Director en ese momento Cadavid Restrepo, era una especie de presión al sector laico oficial para trabajar en un marco delimitado de la renovación y de la Escuela Activa, pero a partir de unos presupuestos escolanovistas inmersos en la tradición católica.

A pesar de lo ya anotado sobre la preocupación del citado Restrepo en

64 P. J. Olano García, Escuelas Manjonianas..., 433.

65 P. J. Olano García, Escuelas Manjonianas..., 433.

66 P. J. Olano García, Escuelas Manjonianas..., 433. 
cuanto a lo que se relacionaba con la inclusión del trabajo manual como método educativo, Restrepo aplaudía a Jiménez López. "Afortunadamente en Colombia se ha abierto ya paso esta idea tan pedagógica" ${ }^{\text {"67 }}$. Y explicaba lo anterior basado en casos vistos en Antioquia:

\begin{abstract}
"En reciente visita a la ciudad de Medellín tuve el gusto de ver aplicados los más modernos métodos, lo mismo en la Escuela de Corrección del Departamento que en un grupo escolar que dirigen en la Plaza de Flórez los beneméritos Hermanos de las Escuelas Cristianas. El Director de Instrucción Pública de aquel Departamento D. Tomás Cadavid Restrepo va a la cabeza de este movimiento, y no solo ha fundado una escuela especial para estudiar y aplicar los nuevos métodos, sino que se esfuerza por introducirlos en todas las escuelas antioqueñas" ${ }^{\text {68. }}$.
\end{abstract}

Una vez más, Antioquia aparecía, junto a Boyacá, como una región líder en la propuesta de implementación de la actividad como principio de la enseñanza.

\title{
3.3. Luis López de Mesa: todos VinCulados por la ACTIVIdAd ORgani- ZADORA Y MEJORADORA, POR UNA "BIOCRACIA"
}

A propósito de Jiménez López y, particularmente, Luis López de Mesa ${ }^{69}$, es importante resaltar que la palabra mágica "actividad", entendida particularmente como algo opuesto a la agitación, no provino solo del discurso de la pedagogía o Escuela Activa. El discurso de los intelectuales de la

67 Félix. S. J. Restrepo, La escuela y la vida..., 610.

68 Félix. S. J. Restrepo, La escuela y la vida..., 610.

69 López de Mesa, vocero y defensor de esos discursos modernistas, desarrollistas y perfeccionistas, si bien no compartía con Miguel Jiménez López la tesis radical acerca del proceso de degeneración de la raza, sí tenía una idea escéptica frente a esta última, sin con ello querer decir que dicha situación estaba por fuera de una solución racional. López de Mesa partía de un estado de imperfección del pueblo colombiano que era susceptible de ser mejorado. Sus apreciaciones estaban basadas en los aportes de los saberes modernos como la biología, la sicología, la fisiología, la higiene, el evolucionismo, y tenían como imágenes referenciales las instituciones modernas, los discursos sobre la renovación racial y nacional del país y los conocimientos de las ciencias modernas. Frente a este supuesto estado de depravación social y anomalía étnico-cultural, la sociedad debía buscar, según este autor, todos los medios posibles para superar su estado de imperfección y mejorarse. 
época, particularmente el de algunos médicos, ya también proponía un activismo como alternativa a la situación de degeneración del país y de la región. Fue así como la actividad sirvió de sustento a esas nuevas visiones educativas, religiosas y eugenésicas ${ }^{70}$, y se planteó como fundamento de las principales propuestas educativas de la época.

Así, dentro de la lógica del movimiento progresivo, la actividad que había de ser tenida en cuenta era la actividad racional, de manera que esta primara sobre la agitación como movimiento falto de organización, carente de racionalidad y sin finalidad alguna y como forma degradada del ser. Se propuso la actividad como principio, pero como aquel a partir del cual se procurara obedecer a un orden y a una finalidad.

Llama la atención entonces que, desde un punto de vista filosófico-ontológico - en nada ajeno, por ejemplo, a ciertas fundamentaciones de la educación activa, a la filosofía vitalista y a lo que el mismo autor denomina "culto por la acción”-, López de Mesa plantee una inquietud inicial como característica de todo lo existente. En el principio de todo está el movimiento y la inquietud. Sin embargo, para López de Mesa dicha inquietud inicial necesita ser cultivada y orientada en "sanas direcciones" (López de Mesa). Lo que quiere decir, ya en el campo de lo humano y lo social, que hay que darle un orden y dirección racionales. De allí precisamente la diferencia entre acción y agitación.

López de Mesa nos habla permanentemente en muchos de sus trabajos de una "inquietud inicial" que funge, a la vez, como principio ontológico y antropológico y que presupone una "energía universal como substancia de todos los seres". Esta energía que "de suyo es acción pura, algo que obra por necesidad de su ser mismo", en el hombre se trata de una "actividad que puede operar sobre sí misma, creando así una nueva dimensión que

70 En la "Civilización contemporánea" los coqueteos de López de Mesa con apreciaciones de corte eugenésico se hacen evidentes, cuando dice, por ejemplo: "Un cultivo de la familia, no solo en su educación social, sino, también, en su vigor genético, es aceptable y conveniente, puede aún autorizar una vigilancia del Estado en cuanto a la salud de los cónyuges y el divorcio, cuando ocurra el disimulo engañoso de graves perturbaciones que hagan posible una nueva generación enferma" (Luis López de Mesa, París: Agencia Mundial de Librerías, 1926), 110. 
no es temporo-espacial, aunque se produzca en el espacio-tiempo, sino introvertible e introspectiva, y que pudiéramos denominar [...] la quinta dimensión o dimensión vital” (López De Mesa, 1970). Referencia completa al final de página

Bajo esos parámetros la inactividad y la falta de referentes fijos no pueden ser más que una muestra de la degradación del ser. Al respecto, sostiene López de Mesa: el "escepticismo y la inacción son dos estados que se corresponden e igualmente apocan el espíritu hasta colocarlo en una depresiva inferioridad. Ante el enigma del universo y el dolor de la vida consciente el hombre busca el refugio de los placeres, el silencio supremo de la muerte o la noble expansión de sus energías en algún empeño laudable: en la acción que afirma su personalidad, la eleva y ennoblece"71. Así, para poder perfeccionarse como raza, el pueblo colombiano y antioqueño estaba llamado a someterse a un Estado biocrático, según López de Mesa ${ }^{72}$, con su conjunto de prácticas y técnicas eugenésicas de selección en las que también había cabida para la educación como práctica selectiva.

Pero volvamos con Restrepo: si se tiene en cuenta su dilatada permanencia en Europa, su conocimiento del país y su formación académica, la opinión citada anteriormente era bien importante. No obstante, al reconocerle algunas bondades al trabajo manual, Restrepo consideraba que Jiménez también lo sobrevaloraba, ya que era exagerado "[...] creer que para todas las disciplinas es auxiliar eficaz el trabajo manual. Si se trata de niños anormales, así es en verdad; pero tratándose de niños de sana constitución y de facultades despiertas, el trabajo manual no es en muchos casos sino un rodeo innecesario" "73. Restrepo reconocía los esfuerzos del ministro Jiménez para "fijarse

71 Luis López de Mesa, "La nueva teoría filosófica”. En Cultura, Vol. I, No. 6, (1915), 418.

72 "También es un error llamar democracia al socialismo o al sovietismo. Es un abuso de etimologías y una mentira institucional. La corriente que engloba estas tendencia más o menos desordenadas pudiera llamarse sencillamente biocracia, el gobierno de la vida, el derecho a vivir, y a vivir lo mejor posible, que invocan las masas del proletariado universal. No es el derecho del trabajo contra el capital, no es el derecho del trabajador a su ganancia, sustancialmente es el grito de la vida que quiere vivir [...] Es la afirmación de la existencia en su conservación, en su recreo, en su procreación y en su perfeccionamiento" (López de Mesa, 1926, 146-147).

73 Félix. S. J., Restrepo, La escuela y la vida..., 610. 
en todo aquello que supone un progreso educativo"74. Y, en tal sentido, lo excusaba de haberse extralimitado al considerar mejor lo nuevo que lo antiguo porque "[...] si en sus palabras hay expresiones exageradas creemos que deben aplicarse por la natural reacción de lo nuevo contra lo viejo, lo cual siempre va un poco más lejos del punto de equilibrio"”75.

\section{A MODO DE CIERRE Y PARA SEGUIR REFLEXIONANDO}

En suma, he aquí que Restrepo proponía que la Escuela Activa pudiera ser parte de la transformación instruccionista, pero claramente en la línea católica, como la expuesta por las escuelas Manjonianas, y en la que la tradición católica no se vería desplazada por tendencias laicas sino, por el contrario, reforzada y renovada metodológicamente. Aún más, la revista "Educación Pública Antioqueña" "76, vocera líder de la oficina gubernamental del ramo, citaba también en 1928 un artículo publicado en la revista "El obrero católico", que ya desde su mismo nombre servía de augurio.

La relación entre la formación propuesta en la Escuela Activa y los obreros católicos no podía ser más estrecha, porque precisamente lo que se buscaba era que los sujetos salieran preparados para desempeñarse "en su trabajo, profesión o destino" "77 y que, a la vez, tuvieran bien claros los principios católicos para regir sus formas de vida. El obrero católico era el culmen del proceso educativo que se buscaba instalar en la Escuela Nueva antioqueña; era el ideal, el producto humano que se debía conseguir. No en vano se hablaba, para entonces, de que alguien que no tenía trabajo, debía, entonces, "conseguir destino". Estaban destinados a trabajar [...] como obreros.

En este contexto histórico se comprenden los postulados sobre los cuales

$74 \quad$ Félix. S. J. Restrepo, La escuela y la vida..., 611.

75 Félix. S. J. Restrepo, La escuela y la vida..., 611.

76 El cambio de nombre de revista de "Instrucción Pública Antioqueña" a "Educación Pública Antioqueña" se produjo a mediados de 1928. Con la Ley Zerda de las postrimerías del siglo XIX, la Revista de Instrucción Pública había reemplazado a los Anales de Instrucción Pública.

77 "Señores Maestros", en "El obrero católico", citado en Educación Pública Antioqueña. Imprenta Departamental de Antioquia. No. 76 (septiembre de 1928), 604. 
se establece la Escuela Activa en nuestro país y en una estrecha relación con el devenir histórico de la burguesía, la industrialización y los nacientes Estados Nacionales en el continente americano. Estos postulados resumen en buena parte este modelo sociopedagógico en el lema de una educación laica, gratuita, única y obligatoria. Laica, en tanto se propende por una formación moral apartada de lo religioso y con orientación estatal. La lucha por el poder estatal con el sector religioso se encontraba en todo su fragor. Gratuita, porque el Estado es llamado a garantizar la educación mínima a la mayoría de la población. Una educación, que si bien no tiene costo aparente para el educando, sí reporta dividendos al Estado por los logros en la instalación primaria de principios en los ciudadanos. Única, si como ya lo hemos visto, debe quedar bajo la orientación hegemónica del Estado, intento que ya se había reforzado con la promulgación de la Ley 39 de $1903^{78}$. Una sola perspectiva permitiría un control centralizado y mensurable. Finalmente, obligatoria, porque se convierte en el requisito indispensable para la formación ciudadana que precisaba ser alcanzada por todos los miembros de la sociedad ${ }^{79}$. Claro que estas características no eran propiamente originales del movimiento escolanovista porque ya desde 1870 había existido en el país una tendencia liberal radical que propugnaba desde 1849 y en la que, finalmente, logró establecerse con la asesoría de una misión de pedagogos alemanes la educación pública, laica, obligatoria, gratuita y basada en la separación entre la Iglesia y el Estado, en la difusión de la ciencia y en la libertad de cátedra ${ }^{80}$.

Religión, moral y educación son tres cuestiones que se articularon en la primera mitad del siglo XX en el departamento de Antioquia; una región de la cual se puede decir, a partir del rastreo histórico realizado, que para entonces pensar en una educación laica le era abiertamente revolucionario y contratradicional. Siguiendo esta lógica de pensamiento, pensar en un

\footnotetext{
78 Ley que, a pesar de entregar la vigilancia y el control de la instrucción a los departamentos, al mismo tiempo estableció unos fines nacionales.

79 Aunque en la Constitución Colombiana de 1886, no se instituyó la educación como una obligación, posteriormente, en la reforma Constitucional de 1936 sí se estableció que la educación debía ser obligatoria, lo cual significaba en principio que se podía producir una secularización de la enseñanza arrebatándole de paso la primacía al clero en este campo.

80 Alfredo Camelo, La educación en el siglo XX..., 34.
} 
hombre que no ha sido educado bajo los preceptos religiosos es considerar la existencia de un individuo incompleto, un peligro para la sociedad, una pieza que no encaja, ya que, como se decía, "el primer conocimiento esencial de la juventud debía ser la religión" $"$.

En tales circunstancias, el posible sujeto de una educación laica no vendría a ser más que un ser incompleto. Se hacía urgente, y ello operaba como único camino, educar al individuo en la religión desde su más tierna infancia, y la mejor forma de hacerlo era estableciendo una conexión entre la religión y la escuela; esta última sería la encargada de educar a los niños y jóvenes bajo los parámetros que la Iglesia dominante imponía, ya que la educación religiosa era concebida como "un saber, saber construido, dotado de nociones, en lo esencial. Saber que tiene su relación práctica, por un lado, con la enseñanza, y, por el otro, con la escuela"82.

Ni pensar, entonces, en una escuela laica, sin religión, y mucho menos en una escuela sin religión católica, porque queda patente de diversas maneras que la educación religiosa fue establecida como un eje articulador naturalizado del currículo escolar en las escuelas antioqueñas en la primera mitad del siglo XX. Así, mientras en otros territorios con el surgimiento progresivo de las escuelas estatales y de una política escolar y educativa orientadas por motivos que cada vez más obedecían a cuestiones económicas y a preocupaciones "ideológicas" en los que cada vez se distanciaba más el poder de la iglesia, en Antioquia, ese no fue ni ha sido el caso.

Finalmente, cabe considerar que a través de la historia de la educación antioqueña este eje articulador del currículo ha tomado tal consistencia que, aunque en la Constitución de 1991 que rige en Colombia en la actualidad se abre la opción de una educación laica en tanto, "se garantiza la libertad de cultos y creencias" en el Artículo $19^{83}$ diciendo que "toda persona tiene derecho a profesar libremente su religión y a difundirla en forma individual o colectiva", la religión Católica sigue siendo enseñada

81 Diderot. Revista Educación Pública Antioqueña (Junio de 1928), 467.

82 Humberto Quiceno, Pedagogía Católica y Escuela Activa en Colombia, 77.

83 Constitución Política de Colombia, Artículo 19, 1991. 
e impartida en las escuelas “oficiales”. Haciendo, una vez más, de paso, y oficial, la religión Católica. Por ello, surge la siguiente pregunta: ¿cómo es posible que en el plan de estudios de las escuelas oficiales se deba incluir la enseñanza de la religión Católica, pero, a su vez, ninguna escuela pueda negarse a admitir un estudiante que profese motivos religiosos diferentes?

Aquí se trata de cuestionarnos acerca de lo que sucede cuando un estudiante no profesa la misma religión que se imparte en la Institución o simplemente no profesa ninguna, generándose así una confusión al no saber cómo marcar la diferencia a la hora de brindar las enseñanzas establecidas a los alumnos de acuerdo a sus intereses, necesidades y creencias. Y, a la vez, una polémica frente a que pese a que la Constitución Nacional garantiza legalmente la libertad de religión, credo y creencias de todo tipo, en los currículos de las escuelas oficiales aún no pareciera hablarse de esta misma libertad.

Finalmente, ¿será que de la teoría a la práctica hay un gran camino que deconstruir en el campo educativo? Y, si es así, ¿cuál es el discurso que se está imponiendo? ¿El de las escuelas antioqueñas oficiales católicas de principios de siglo XX o el de las leyes propicias a la diversidad dictadas por el Estado a finales de este mismo siglo? ¿Será que es posible pensar una escuela laica, una escuela más allá de lo religioso y que estas prácticas religiosas, finalmente hagan parte de la intimidad de las familias y de los sujetos particulares responsables de sus propias decisiones espirituales?

\section{Bibliografía}

\section{Fuentes primarias}

Arango, Abelardo. "Estadísticas y Reflexiones del estudio psicopedagógico de los menores”. En Educación Antioqueña. Universidad Nacional. No. 2 (diciembre de 1935).

Boletín masónico, Bogotá, junio 1º 1876.

Cadavid Restrepo, Tomás. "Para Dios y para la vida". Revista Educación Pública Antioqueña. (Febrero de 1928).

Constitución Política de la República de Colombia, agosto 5 de 1886. Ar- 
tículo 38.

Decreto Nacional 491. En Educación Antioqueña. Imprenta Departamental. No. 9-10 (marzo de 1904).

De Víctor Hugo. Lo que es la enseñanza sin religión. Revista Educación Pública Antioqueña. Junio de 1928.

Diderot, Revista Educación Pública Antioqueña, junio de 1928.

Educación, El Lábaro, Órgano oficial de la Arquidiócesis de Medellín, No. 18, diciembre de 1905.

El Colombiano, La Escuela sin Dios. Periódico Político-Religioso, Órgano del Directorio Conservador del Departamento de Antioquia, Serie XXIII, No. 223, (20 de febrero de 1914).

El Colombiano, Manifestación de protesta que hace la liga de damas católicas. Medellín, Colombia, Año XIX. (enero de 1931).

El Monitor. Tomo I, Medellín. (17 de julio de 1872).

Henao, J. Apertura de la Conferencia Pedagógica, 15 de diciembre de 1909. En Instrucción Pública Antioqueña. Imprenta Departamental de Antioquia. No. 23 (enero de 1910).

Jiménez López, Miguel. La escuela y la vida. (Lausanne: Imprimieries Réunies S.A, 1928)

Lopera, Ismael. “Lo que es la enseñanza sin religión”. En Educación Pública Antioqueña No. 69 (junio de 1928).

López de Mesa, Luis. "La nueva teoría filosófica”. En Cultura, Vol. I, No. 6, (1915), 418-432.

López de Mesa, Luis. Civilización contemporánea. París: Agencia Mundial de Librería, 1926.

López de Mesa, Luis. Disertación sociológica. Medellín: Editorial Bedout. 1970.

Murillo Toro, Manuel. Mensaje al Congreso en 1874. En Obras Selectas. Bogotá Ed. Cámara de Representantes, 1979.

Nieto Caballero, Agustín. Los Maestros. Bogotá: Editorial Antares Ltda. 1963.

Olano García, P. J. Escuelas Manjonianas. Contribución a la Escuela Activa. En Educación Pública Antioqueña. No. 73 (junio de 1928).

142 Palacio, Eduardo. “Instrucción”. En Instrucción Pública Antioqueña. (junio de 1913), 47-48.

Palacio, Eduardo. "Instrucción que el Obispo de Antioquia dirige a los 
directores y maestros de escuelas y colegios de su Diócesis". En Instrucción Pública Antioqueña. No. 50. Imprenta Departamental de Antioquia. (octubre de 1913).

Reglamento para las Escuelas. En Revista Educación Pública Antioqueña, No. 69. Serie V. (Febrero de 1928).

Restrepo, Félix. S. J. La escuela y la vida. En Educación Pública Antioqueña. $N^{\circ} .76$ (septiembre de 1928): 609.

"Señores Maestros". En "El obrero católico", citado en Educación Pública Antioqueña. Imprenta Departamental de Antioquia. No. 76 (septiembre de 1928).

Thomsom. Las escuelas y los maestros. En Estudios Pedagógicos. Serie 1, No. 2. Medellín, (julio 10 de 1913).

Uribe Uribe, Rafael. Por la América del Sur. Tomo I. Bogotá D.E.: Editorial Kelly, 1955.

Von Karman, Elmer. "El hurto como síntoma de enfermedad moral”. En Educación Antioqueña. Imprenta Departamental. No. 3-4. (mayo de 1939).

Zuluaga y Gutiérrez, A. La cuestión cultural en Colombia. "Esto matará aquello”. Capítulo III. En Revista Claridad. Año 1, No. 28 (septiembre de 1930): 1223

\section{Fuentes secundarias}

Archila, Mauricio. "La clase obrera colombiana, 1886-1930", En Álvaro Tirado Mejía, ed., Nueva Historia de Colombia, Vol. 3, Bogotá: Planeta, 1989.

Camelo, Alfredo. La educación en el siglo XX. La escuela colombiana en la primera mitad del siglo XX. Revista Educación y Cultura, No. 50-51 (Agosto de 1999): 35.

Constitución Política. Congreso de la República. Colombia, 1991.

Donzelot, Jacques. La policía de las familias. Valencia. Pre-Textos, 1979.

Fend, Helmut. Geschichte des Bildungswesens. Der Sonderweg im europäischen Kulturraum. Wiesbaden. VS Verlag für Sozialwissenschaften, 2006.

Foucault, Michael. Vigilar y Castigar. Buenos Aires, Argentina: S. XXI Editores, 2002.

Henderson, James. La modernización en Colombia. Los años de Laureano 
Gómez. Medellín: Editorial Universidad de Antioquia, 2006. Herrera, Martha Cecilia. Modernización y Escuela Nueva en Colombia. Bogotá: Plaza y Janés Editores, 1999.

Herrera Beltrán, Claudia \& Adán Rubiano, Tania. Las infancias en imágenes cien años después de la independencia de Colombia: Iconografía e Historia. XIV Encuentro de Latinoamericanistas Españoles, 2010. Martínez, Frédéric. El nacionalismo cosmopolita. La referencia europea en la construcción nacional en Colombia, 1845-1900. Bogotá: Banco de la República / Instituto Francés de Estudios Andinos, 2001.

Melo, Jorge O. Medellín: Historias y representaciones imaginadas. Seminario: Una mirada a Medellín y al Valle de Aburrá, Memorias, (1993).

Ospina-Cruz, Carlos. El mercado de las almas versus el proyecto moderno instruccionista en Antioquia, 1903-1930. Revista Historia de la Educación Colombiana. RudeColombia. Vol. 13. No. 13, (2010): 98. Ospina-Cruz Carlos. El proyecto moderno instruccionista en Antioquia. Ley 39 de 1903, modos de instrucción y enclaves de resistencia. (Tesis Doctoral. Medellín: Universidad de Antioquia. 2011).

Quiceno Castrillón, Humberto. Pedagogía católica y escuela activa en Colombia (1900-1935). Santafé de Bogotá: Ediciones Foro Nacional por Colombia, 1988.

Andrés Ríos Molina, Identidad y religión en la colonización del Urabá Antioqueño. En Tabula Rasa No. 1 [en línea]. Recuperado el 24 de abril de 2011 en http://www.revistatabularasa.org/numero_uno/ Mospina.pdf-, 2003.

Verdugo Moreno, Pedro C. Educación y política en el siglo XIX: Los modelos Laico-Liberal y Católico-Conservador. Revista Historia de la Educación Colombiana. Rudecolombia. No. 6-7, (2004), 81-98.

Para citar este artículo: Ospina Cruz, Carlos Arturo y Runge Peña, Andrés Klaus. "La educación laica en Antioquia durante el primer cuarto

144 del siglo xx: una historia de solapamientos y combinatorias", Historia Caribe Vol. XII No. 30 (Enero-Junio 2017): 107-144. DOI: http://dx.doi. org/10.15648/hc.30.2016.5 